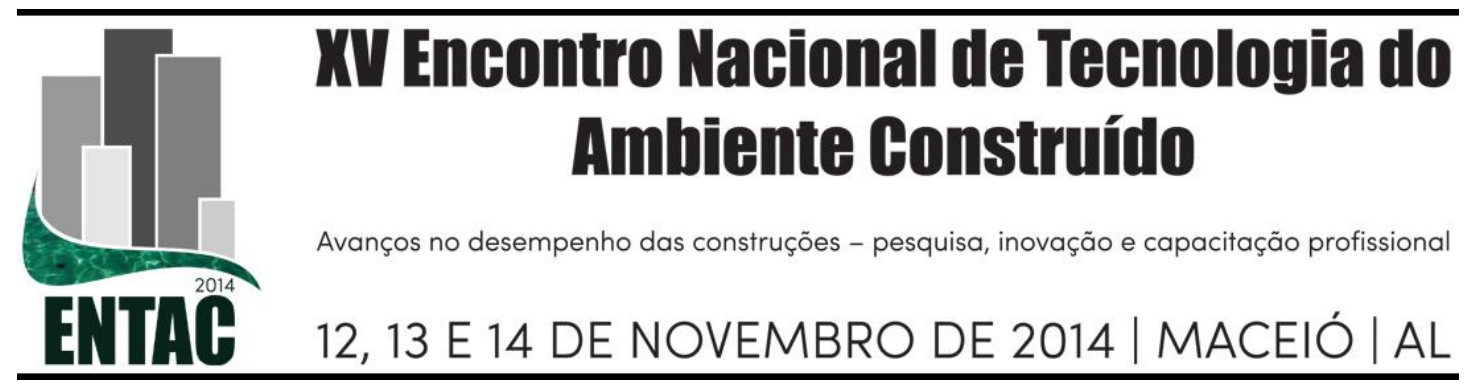

\title{
CARACTERIZAÇÃO DO PAPEL KRAFT DE EMBALAGENS VISANDO O EMPREGO COMO FIBRAS EM COMPÓSITOS CIMENTÍCIOS
}

CARVALHO, Patrícia (1); VIEIRA, Isabella (2); AURIONE, Daniela (3);

CARDOSO, Thiago (4); CARASEK, Helena (5); CASCUDO; Oswaldo (6)

(1) PPG GECON - Universidade Federal de Goiás, (62) 91407673, patriciaefc@gmail.com, (2)

Universidade Federal de Goiás, isabella.p.vieira@gmail.com, (3) Universidade Federal de Goiás, dani_aurione@hotmail.com, (4) Universidade Federal de Goiás, thiagocostacaardoso@gmail.com, (5) PPG GECON - Universidade Federal de Goiás, hcarasek@gmail.com, (6) PPG GECON- Universidade Federal de Goiás, ocascudo@gmail.com

\section{RESUMO}

Visando dar uma destinação viável às embalagens de papel kraft de materiais da construção civil, este trabalho se propõe a caracterizar esse material para que possa ser empregado em compósitos cimentícios. Para tal, foram estudadas tanto amostras de papel em sua forma original, quanto amostras já processadas mecanicamente na forma de fibras. Os ensaios realizados foram de caracterização morfológica, bem como de caracterização física e mecânica. Em relação a outros materiais de origem vegetal e polpas celulósicas já estudadas para os mesmos fins, as fibras de papel kraft apresentaram características favoráveis à utilização em compósitos cimentícios, uma vez que apresentaram relação de aspecto adequado, menores valores de absorção de água, capacidade de alongamento superior à $5 \%$ e boa resistência às variações de umidade e temperatura.

Palavras-chave: Papel kraft, Fibras, Argamassa.

\begin{abstract}
In order to give a viable destination for kraft paper construction materials, this study aims to characterize the material so it can be used in cement composites. To this, samples of paper were used in their original form, as for samples already processed mechanically in the form of fibers. The tests were performed as well as morphological characterization of mechanical and physical characterization. Compared to other materials of vegetable origin and cellulosic pulps have been studied for the same purposes, kraft paper fibers showed favorable characteristics employment taking appropriate aspect ratio, smaller values of water absorption, elongation greater than $5 \%$ and good resistance to humidity and temperature variations.
\end{abstract}

Keywords: Kraft paper, Fibers, Mortar.

\section{INTRODUÇÃO}

O setor da construção civil, embora ainda responda por $40 \%$ de todo o resíduo produzido pela atividade humana e $75 \%$ do consumo de recursos naturais no país (LAURIANO, 2013) vem buscando reverter essa realidade. A nova norma de desempenho juntamente com as leis de proteção ambiental tem se apresentado como aliada na busca pela sustentabilidade na construção à medida que estabelece as obrigações de cada participante dentro da cadeia construtiva. Quanto à mitigação dos impactos gerados pelos resíduos, esforços devem voltar-se primeiramente para não geração e, em seguida, para reutilização. No entanto, no que se refere a reutilização, grande parte dos resíduos 
passíveis de reaproveitamento acaba ocioso por falta de informação. Assim, este trabalho vem contribuir com o conhecimento acerca de embalagens de papel kraft (sacarias de cimento e cal), as quais apresentam grande potencial para reutilização na forma de fỉbras para produção de compósitos cimentícios, apresentando sua caracterização e avaliação de propriedades para aplicação.

\section{REVISÃO BIBLIOGRÁFICA}

Segundo levantamento realizado em indústrias papeleiras que fornecem embalagens para fábricas de cimento e de cal, as fibras mais empregadas são as do gênero Pinus, que são fibras do tipo coníferas e longas.

Moraes Neto, Teles e Rodrigues (2009) realizaram a caracterização de 5 diferentes tipos de madeira Pinus frequentemente encontrados no Brasil. Os intervalos de valores encontrados nessa caracterização estão apresentados a seguir, na Tabela 1.

Tabela 1- Valores mínimos e máximos obtidos na caracterização de madeiras

Pinus (MORAES NETO; TELES; RODRIGUES, 2009)

\begin{tabular}{|c|c|c|c|c|c|c|c|c|c|}
\hline \multicolumn{2}{|c|}{$\begin{array}{c}\text { Módulo de } \\
\text { elasticidade } \\
\text { estática (MPa) }\end{array}$} & \multicolumn{2}{|c|}{$\begin{array}{c}\text { Módulo de } \\
\text { ruptura à flexão } \\
\text { estática (MPa) }\end{array}$} & \multicolumn{2}{|c|}{$\begin{array}{l}\text { Cisalhamento } \\
\text { paralelo às } \\
\text { fibras (MPa) }\end{array}$} & \multicolumn{2}{|c|}{$\begin{array}{c}\text { Compressão } \\
\text { paralela às } \\
\text { fibras (MPa) }\end{array}$} & \multicolumn{2}{|c|}{$\begin{array}{l}\text { Compressão } \\
\text { perpendicular } \\
\text { às fibras }(\mathrm{MPa})\end{array}$} \\
\hline Seca & & & & $\mathrm{Sec}$ & & & & & \\
\hline $\begin{array}{c}6856- \\
9756\end{array}$ & $\begin{array}{c}5807- \\
8285\end{array}$ & $0-84$ & $34-$ & $\begin{array}{r}6,7 \\
11\end{array}$ & $\begin{array}{c}4,1- \\
5,5\end{array}$ & $29-43$ & $14-22$ & $\begin{array}{c}4,5- \\
6,3\end{array}$ & $\begin{array}{c}2,6- \\
4,3\end{array}$ \\
\hline
\end{tabular}

Tal variabilidade na matéria prima de origem vegetal tende a ser reduzida dentro da indústria papeleira por meio do controle dos processos de fabricação, especialmente na etapa de produção das folhas de celulose. Para produção do papel kraft empregado nas sacarias de cimento e de cal, a celulose empregada é advinda do processo kraft de polpação, que se trata de um processo químico para transformar a madeira em uma massa de fibras individualizadas, cujo objetivo principal é a liberação das fibras de celulose, o que ocorre pela ruptura das ligações entre as fibras no interior da estrutura da madeira.

A composição química das fibras é fator definitivo das suas características físicas, além de implicar em maiores gastos ou não no processo de polpação. Assim, a composição química deve ser analisada a fim de se definir quais suas possibilidades de aplicação em compósitos cimentícios. Na Tabela 2 estão apresentados valores da constituição química de fibras Pinus encontrados por Balloni (2009), Vasconcelos (2005), Foelkel (1983) e Copur e Tozluoglu (2007) e, na Tabela 3 estão apresentadas faixas de variação dos resultados da caracterização física e mecânica de diversos autores, compilados por Magalhães (2009).

Tabela 2 - Composição química de fibras de madeira Pinus (em \%)

\begin{tabular}{c|c|c|c|c}
\hline Composto & Balloni & Vasconcelos & Foelkel & Copur e Tozluoglu \\
\hline Holocelulose & 68,6 & 70,26 & & 75,5 \\
\hline Celulose & - & - & & 46,8 \\
\hline Lignina & 28,2 & 29,74 & $26-29$ & 26,1 \\
\hline
\end{tabular}




\begin{tabular}{c|c|c|c|c}
\hline Composto & Balloni & Vasconcelos & Foelkel & Copur e Tozluoglu \\
\hline Extrativos & 3,0 & 4,5 & $2,5-4,5$ & 1,9 \\
\hline Cinzas & 0,4 & - & & 0,4 \\
\hline
\end{tabular}

Tabela 3 - Caracterização físicas e mecânicas de fibras de celulose Pinus (MAGALHÃES, 2009)

\begin{tabular}{c|c|c|c|c}
\hline Propriedade & $\begin{array}{c}\text { Massa } \\
\text { específica real } \\
\left(\mathrm{kg} / \mathrm{m}^{3}\right)\end{array}$ & $\begin{array}{c}\text { Absorção } \\
\text { máxima (\%) }\end{array}$ & $\begin{array}{c}\text { Resistência à } \\
\text { tração }(\mathrm{MPa})\end{array}$ & $\begin{array}{c}\text { Módulo de } \\
\text { elasticidade }(\mathrm{GPa})\end{array}$ \\
\hline Faixa de variação & 1200 a 1500 & 400 & 300 a 500 & 10 a 40 \\
\hline
\end{tabular}

O teor de lignina nas pastas celulósicas advindas do processo kraft podem cair até valores considerados baixos. Esse número pode ser determinado de forma indireta, por meio de um fator de conversão aplicado ao número kappa, que indica a deslignificação do processo de polpação. Segundo dados levantados juntamente com indústria de celulose para sacarias de papel kraft, os valores kappa encontram-se entre 52 e 56 na fase de polpação, podendo decair até 3 pontos na fase de depuração. Para madeiras, a norma TAPPI T $236 \mathrm{~cm}-85$, utiliza o fator de conversão 0,15 , ou seja, essas polpas celulósicas podem apresentar teores de lignina inferiores à $7 \%$. Tal fato é bastante relevante por se tratar de um composto com baixa resistência ao meio alcalino encontrado em compósitos cimentícios, o que o torna vantajoso em relação a outras fibras vegetais empregadas na produção desses compósitos.

\section{MATERIAIS E MÉTODOS}

Para realização do estudo foram empregadas amostras de papel em diferentes condições e realizados ensaios tanto para análise morfológica quanto para determinação das características físicas e mecânicas. Os materiais e métodos adotados são explanados a seguir.

\subsection{Materiais}

Para realização do estudo foram utilizadas embalagens de cimento (A) e de cal (B), tanto novas quanto embalagens usadas, recolhidas em canteiros de obras. As amostras foram estudadas em fragmentos do papel ou já na forma de fibras processadas para aplicação como reforço em matriz cimentícia. Ainda, foram variadas as amostras em função da região da sacaria, sendo elas:

- $\quad$ sem cola e sem tinta (SCT);

- com tinta (CT); e

- com cola (CC).

Para analisar os possíveis efeitos das variações nas condições de temperatura e umidade ambiente, alguns ensaios foram realizados em amostras em três condições:

- $\quad$ amostras em condições ambientes (GA); 
- amostras que passaram por 5 ciclos de temperatura $\left(25^{\circ} \mathrm{C}\right.$ e $\left.60^{\circ} \mathrm{C}\right)$ - grupo secagem (GS); e

- amostras que passaram por 5 ciclos de variação de umidade e temperatura, tendo sido saturadas e em seguida secas a $60^{\circ} \mathrm{C}$ - grupo saturação e secagem (GSS).

\subsection{Métodos}

Os ensaios realizados para caracterização do papel kraft proveniente de embalagens bem como as amostras empregadas em cada análise estão apresentadas na Tabela 4, a seguir.

Tabela 4- Resumo dos ensaios realizados

\begin{tabular}{c|c|c|c}
\hline Análise & Norma / Procedimento & \multicolumn{2}{|c}{ Amostra } \\
\hline $\begin{array}{c}\text { Análise da } \\
\text { microestrutura }\end{array}$ & $\begin{array}{c}\text { Visualização no MEV da } \\
\text { morfologia, medida do } \\
\text { comprimento e diâmetro } \\
\text { médio das fibras }\end{array}$ & Papel novo & FCT, CT, CC \\
\cline { 3 - 4 } & -- & Papel novo & SCT, CT, CC \\
\hline $\begin{array}{c}\text { Absorção de } \\
\text { água inicial }\end{array}$ & -- & Papel Novo & SCT \\
\hline $\begin{array}{c}\text { Absorção de } \\
\text { água total }\end{array}$ & NBR NM ISO 536:2000 & Papel novo & SCT, CT, CC \\
\hline $\begin{array}{c}\text { Gramatura } \\
\text { Grau de }\end{array}$ & NBR IEC 60450:2009 & $\begin{array}{c}\text { Fibra (de } \\
\text { papel usado) }\end{array}$ & GA \\
\hline $\begin{array}{c}\text { Resistência à } \\
\text { tração }\end{array}$ & ASTM D 828 - 97 & Papel novo & GA, GS, GSS \\
\hline Alongamento & ASTM D 828 - 97 & & \\
\hline
\end{tabular}

A análise da microestrutura do papel foi realizada por meio de imagens obtidas em Microscópio Eletrônico de Varredura (MEV) Jeol JSM-6610 - Scanning Electron Microscope. Com auxílio do programa computacional ImageJ foi possível obter o comprimento e diâmetro médios das fibras.

A absorção de água das embalagens de papel kraft foi medida a partir de dois métodos, sendo eles absorção total e absorção inicial. Para absorção total foram coletadas três amostras de cada uma das embalagens com dimensões de $5 \mathrm{~cm}$ x $5 \mathrm{~cm}$ que foram retiradas da região central dos sacos, sem tinta e também sem abranger as dobras de fechamento dos sacos, as quais possuem cola. As amostras tiveram suas massas determinadas e, em seguida foram colocadas em estufa à temperatura de $50^{\circ} \mathrm{C}$ até atingirem constância de massa. Após a secagem, as amostras foram novamente pesadas e então, saturadas em água à temperatura de $23^{\circ} \mathrm{C}$ por 24 horas. Ao final dessa etapa, as amostras tiveram o excesso de água retirado com pano úmido, sendo então registradas novamente as massas das amostras. A absorção de água das embalagens foi dada pela Equação 1, exibida a seguir.

$$
A(\%)=\frac{M u-M s}{M s} \times 100
$$


Onde, $\mathrm{A}(\%)=$ Absorção de água percentual

$\mathrm{Mu}=$ massa úmida

Ms $=$ Massa seca

O processo de secagem prévia das amostras para o ensaio de absorção total pode provocar a aproximação das lamelas das fibras, alterando sua porosidade e, consequentemente, sua capacidade de absorver água. Assim, também foi realizado o ensaio de absorção inicial, no qual as amostras não foram previamente secas, estando com umidade ambiente. As amostras foram imersas em água por 30 segundos e em seguida foram registradas suas massas. O valor da absorção foi dado por meio de cálculo, como o da absorção total. Para tal avaliação foram utilizadas amostras do papel sem tinta e sem cola, bem como, com tinta e com cola.

Foram realizados ensaios para medir o Grau de Polimerização (GP) das fibras após o processamento das embalagens, a fim de avaliar sua resistência à possível degradação causada pelo processo de transformação da sacaria em fibra, bem como às condições adversas de temperatura e umidade à que as embalagens possa ter sido submetidas em obra. Esse ensaio foi realizado em fibras advindas de embalagens B. As amostras foram retiradas aleatoriamente de um grande volume de sacarias já processadas, as quais foram recolhidas em canteiros de obras, ou seja, submetidas a condições variadas de umidade e temperatura.

Ademais, foram realizados ensaios normalizados em amostras de papel para a determinação do alongamento e resistência à tração. No ensaio foi utilizado um texturômetro da marca Stable Mycro System, modelo TA.XT, com distância entre as garras de $122 \mathrm{~mm}$. As dimensões das amostras seguiram orientações da norma D 828 (ASTM, 1997).

\section{RESULTADOS E DISCUSSÕES}

Os resultados obtidos na caracterização do papel kraft das sacarias de embalagens estão apresentadas a seguir.

\subsection{Análise da microestrutura}

As imagens obtidas por meio do $\mathrm{MEV}$ das diferentes regiões das embalagens são apresentadas na Figura 1, a seguir. Pode-se verificar a presença da cola sobre as tramas de fibras retiradas de regiões de lacre das embalagens (fundo e boca dos sacos) e também da tinta de impressão. Comparando-se as imagens apenas do papel e do papel com cola, percebe-se uma crosta formada pela cola e, em relação ao papel com tinta é visível uma película sobre as fibras. Possivelmente, tanto a cola quanto a tinta acabam "impermeabilizando a fibra", alterando suas propriedades de absorção de água e variação volumétrica.

Quanto ao efeito das diferenças de temperatura e umidade aplicadas às amostras, pode-se observar maiores alterações na situação em que as amostras foram submetidas às duas condições, saturação e secagem. 


\section{Figura 1- Imagens obtidas por MEV de diferentes regiões do papel}

a) Imagem do papel sem cola e sem tinta b) Imagem do papel com cola c) Imagem do papel com tinta

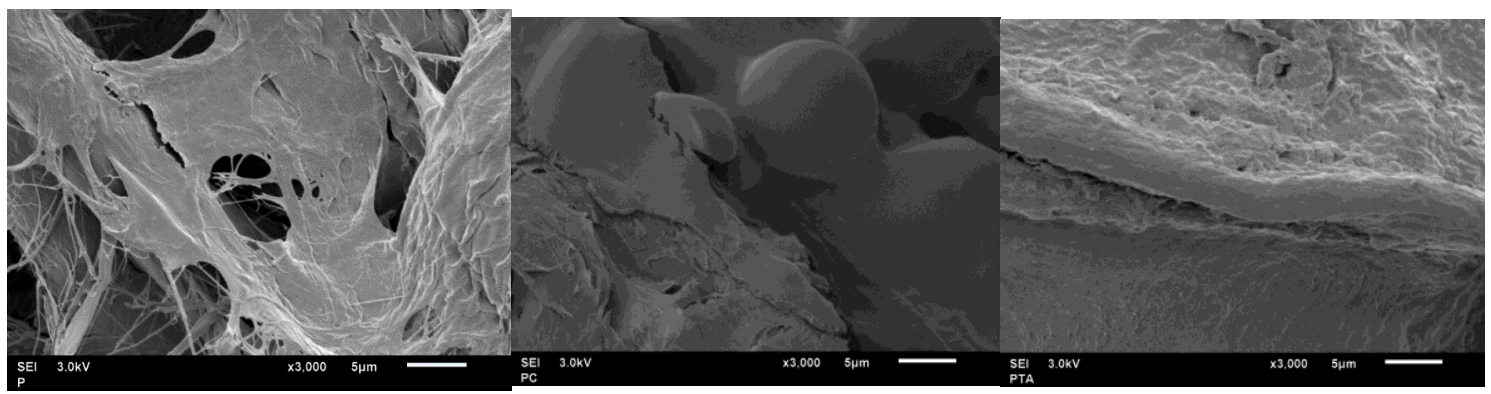

Nas Figuras 2-c e 2-f, as amostras apresentam-se mais achatadas e com maior intensidade de rugosidade, essa alteração possivelmente é provocada pela saída de água do interior da estrutura porosa da fibra, que faz com as lamelas se aproximem umas das outras. Foi verificado que tal variação na morfologia da fibra tende a ser definitiva, isto é, a fibra uma vez achatada, não voltará à sua forma original. Esse comportamento é positivo para o emprego das fibras em compósitos cimentícios, pois a variação volumétrica da fibra ao longo do tempo já no compósito pode causar desagregação à matriz, fazendo com que perca sua função.

Figura 2- Imagens de fibras A e B: (a) e (d) em condições ambiente, (b) e (e) submetida à temperatura, (c) (f) submetida à saturação e secagem
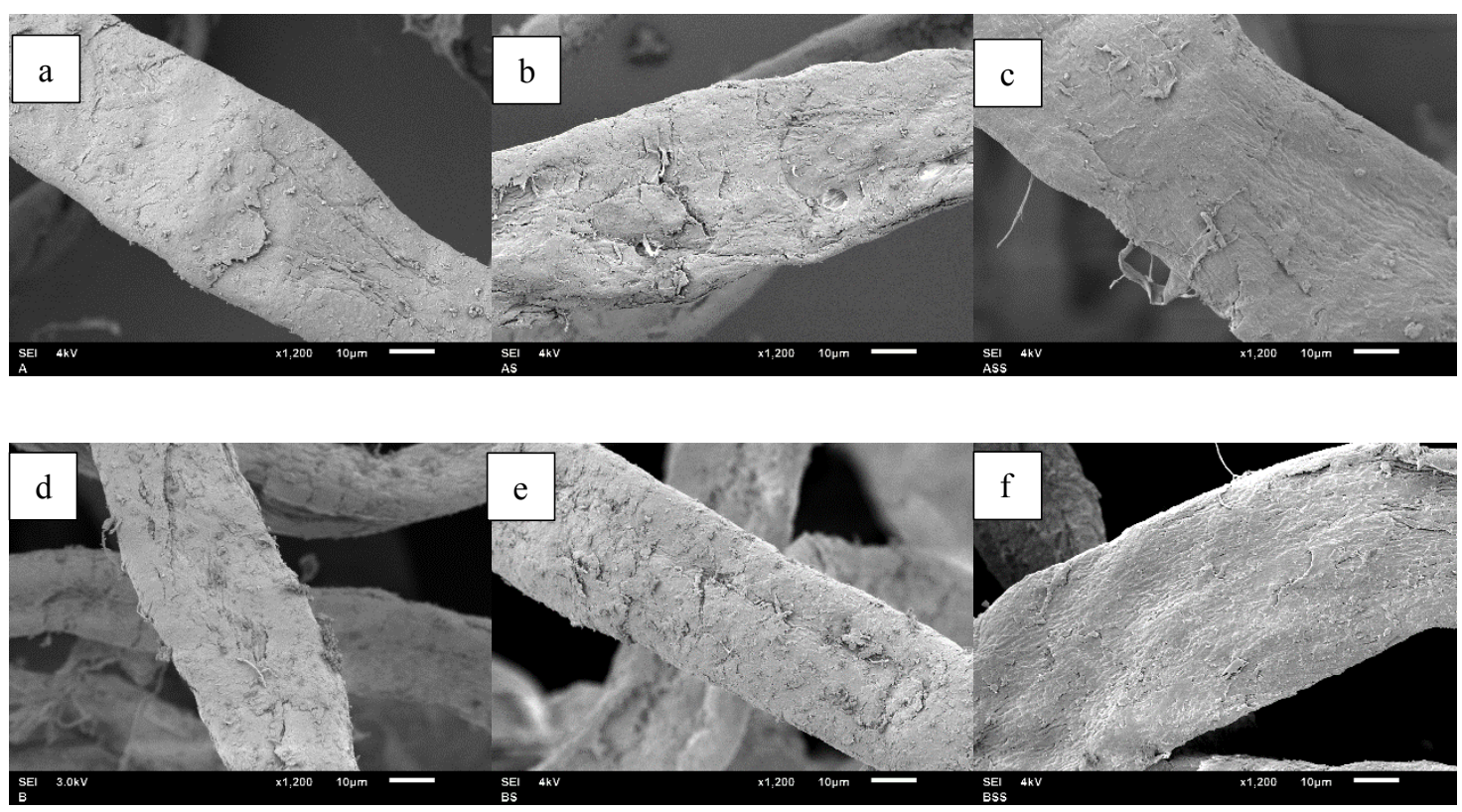

O comprimento médio das fibras advindas do processamento do papel kraft foi de $1,75 \mathrm{~mm}$ e o diâmetro médio de $28 \mu \mathrm{m}$. Assim, a relação de aspecto para as fibras obtidas do processamento do papel kraft é de 62,5. Quanto à forma das fibras, o comprimento é fator limitador do seu desempenho, pois necessitam de um comprimento mínimo para ter ancoragem à matriz, porém, se muito longas, absorvem altas tensões o que pode levar a 
ruptura. Segundo Savastano (2000), a eficiência do compósito não depende de um longo comprimento de ancoragem, visto em seu estudo que o desempenho das fibras celulósicas, as quais apresentam comprimentos médios entre 1 e $2 \mathrm{~mm}$, foi superior ao de fibras vegetais de maiores comprimentos. Mas sim, de uma relação de aspecto bem proporcionada, ou seja, entre 50 e 200.

\subsection{Absorção de água e gramatura}

Os resultados obtidos nos ensaios de absorção de água e gramatura das folhas de papel kraft são apresentados na Tabela 5, a seguir.

Tabela 5 - Resultados médios dos ensaios de absorção de água e gramatura do papel kraft

\begin{tabular}{c|c|c|c|c}
\hline \multicolumn{2}{c|}{ Ensaio } & $\begin{array}{c}\text { Sem cola e sem } \\
\text { tinta }\end{array}$ & Com tinta & Com cola \\
\hline \multirow{2}{*}{ Absorção total (\%) } & A & 131,2 & - & - \\
\cline { 2 - 5 } & B & 154,6 & - & - \\
\hline \multirow{2}{*}{ Absorção inicial (\%) } & A & 59,4 & 49,8 & 26,6 \\
\cline { 2 - 5 } & B & 67,4 & 65,2 & 30,6 \\
\hline \multirow{2}{*}{ Gramatura $\left(\mathrm{g} / \mathrm{m}^{2}\right)$} & A & 87,3 & 89,2 & - \\
\cline { 2 - 5 } & B & 83,9 & 84,7 & - \\
\hline
\end{tabular}

Em relação à absorção total de água, percebe-se que as fibras do papel kraft das sacarias estudadas, que são de madeira pinus, possuem menor absorção de água total do que as fibras vegetais estudadas por Savastano (2000), que chegaram até a 643\%. Notou-se também que a presença da cola e da tinta da sacaria alteram a absorção inicial, reduzindoa. Embora a redução da absorção de água seja um fator positivo quando em compósitos cimentícios, a presença da tinta e da cola pode alterar outras propriedades, como a capacidade de alongamento e resistência da fibra, pois enrijecem sua estrutura.

A gramatura da embalagem $\mathrm{B}$ é ligeiramente inferior à da embalagem $\mathrm{A}$. Para efeitos de desempenho em compósitos, tal diferença pode ser considerada desprezível, visto que a gramatura indica a densidade da trama de fibras do papel, e não uma propriedade direta da fibra. Segundo indústria papeleira consultada para o levantamento de dados, a massa celulósica (polpa acrescida de produtos químicos para formação da folha) é a mesma empregada para os sacos de cimento e de cal, sendo alterada apenas a orientação das fibras. Para a região do papel com a cola não foi possível determinar a gramatura, pois são regiões com 2 ou 3 camadas de folhas e a separação dessas acaba provocando o rasgo ou mesmo uma separação não uniforme da parcela de cola.

\subsection{Grau de polimerização}

Os resultados obtidos estão apresentados na Tabela 6. Estudos mostram que com o tempo o valor do GP tende a cair, indicando perda de desempenho mecânico do material, no entanto a sua resistência mecânica independe dos valores de GP quando ele é superior a 500. (MARTINS, 2007; ZIRBES; ROLIM; ZÜRN, 2005). Sendo assim, os valores de GP 
obtidos para as amostras em estudo são considerados altos, indicando que o processamento mecânico para transformação do papel em fibra não prejudicou a sua resistência e, ainda, devem apresentar uma boa durabilidade em compósitos cimentícios, visto que o grau de agressividade para reduzir os valores de GP a valores inferiores a 500 deve ser alto.

Tabela 6 - Resultados do ensaio de Grau de Polimerização (adimensional)

\begin{tabular}{c|c|c|c}
\hline & Ensaio 1 & Ensaio 2 & Média \\
\hline Amostra 1 & 852 & 911 & 881,5 \\
\hline Amostra 2 & 909 & 800 & 854,5 \\
\hline
\end{tabular}

\subsection{Resistência à tração e alongamento}

Nas Figuras 3 e 4 estão apresentados os resultados obtidos nos ensaios de resistência à tração e alongamento e seus coeficientes de variação (cv), em percentual, realizados em amostras de papel submetidas às diferentes condições. Embora os resultados reflitam as características da trama do papel e não diretamente das fibras dispersas, eles possibilitam uma análise do material, especialmente acerca das suas variações.

Figura 3- Resultados médios dos ensaios de resistência à tração

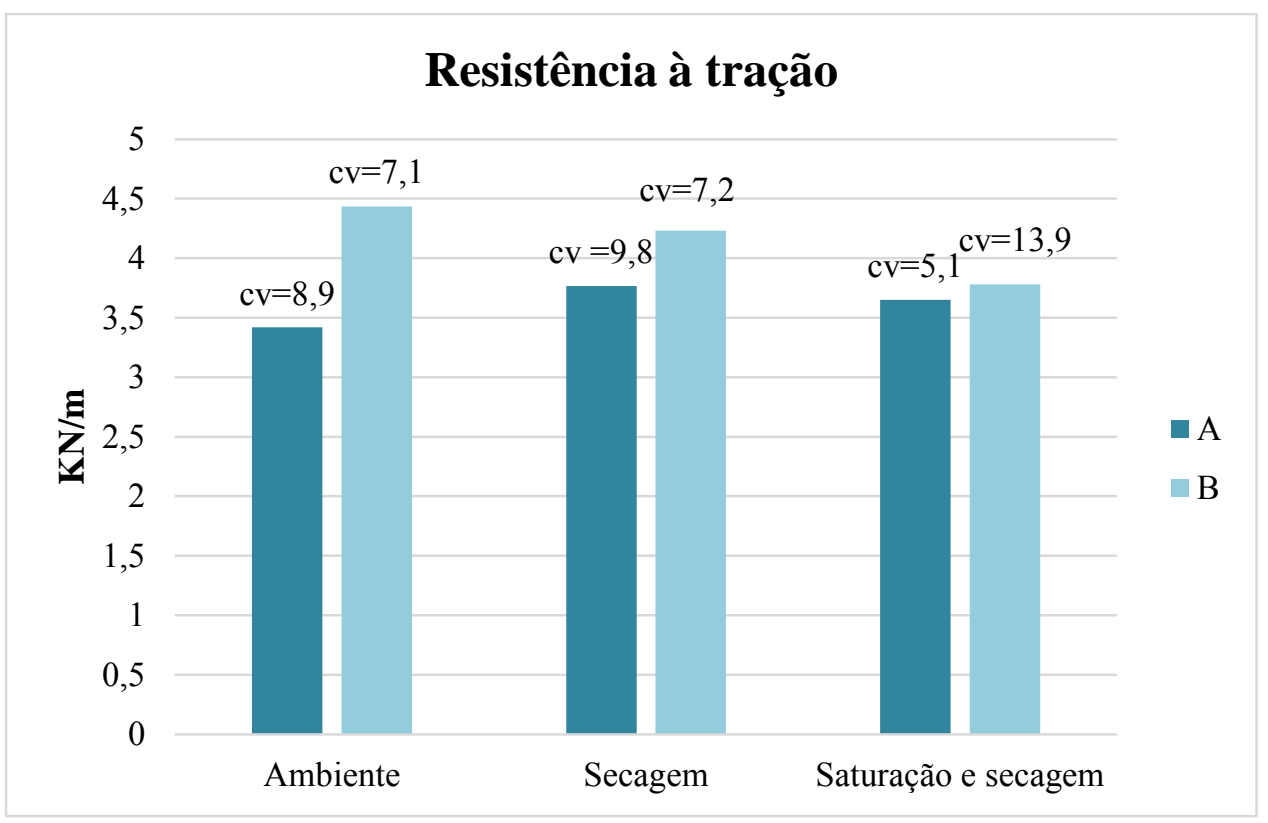


Figura 4 - Resultados médios dos ensaios de alongamento

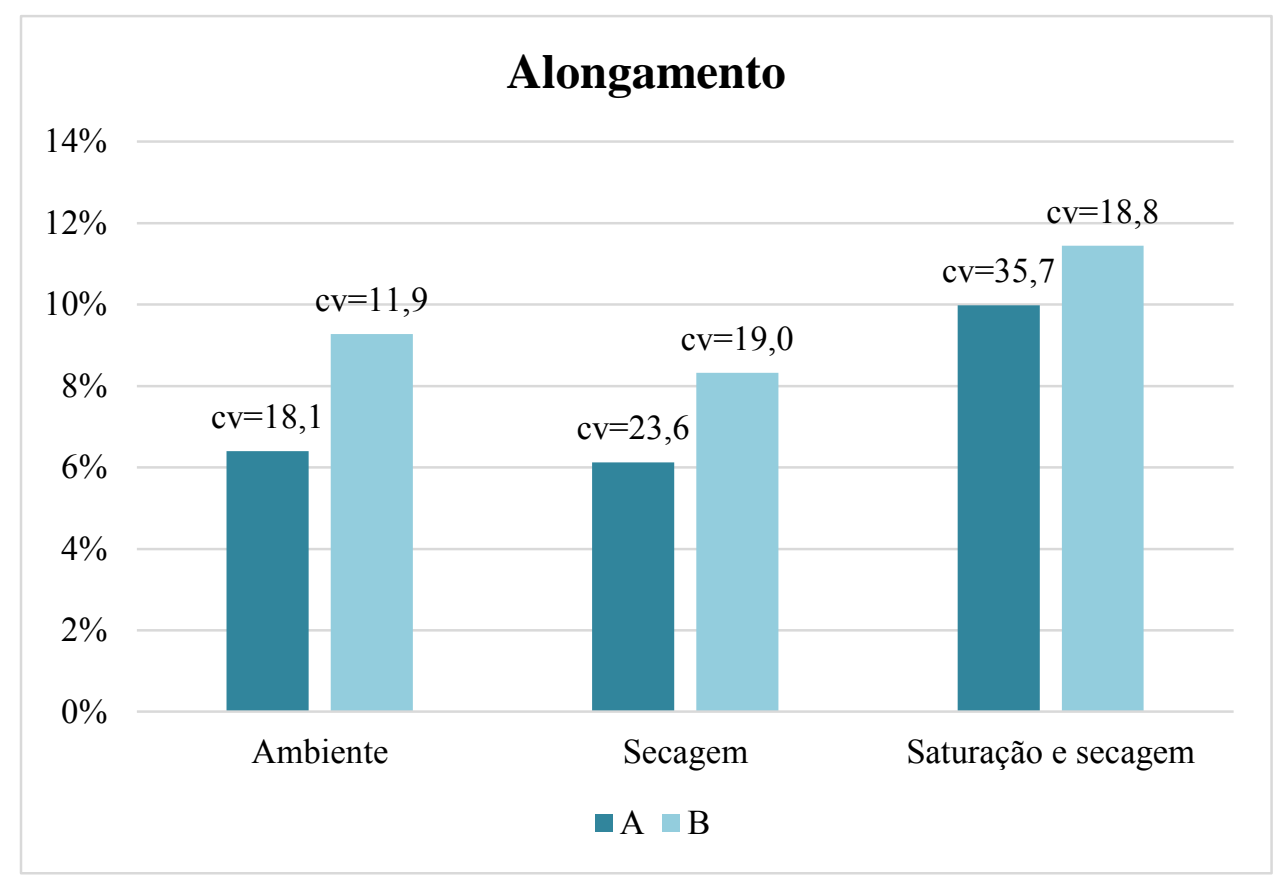

Analisando-se os gráficos percebe-se que há uma grande dispersão nos resultados dentro de um mesmo grupo. No entanto, as amostras B, de sacarias de cal, apresentam maiores resultados. Para esse grupo, o efeito da secagem e da saturação e secagem tendem a reduzir a capacidade de resistência à tração do papel, porém em níveis muito baixos. Já para a sacaria de cimento (amostra A), a qual deve apresentar uma trama de fibras mais fechada, os ciclos não alteraram suas propriedades de resistência.

Já quanto ao alongamento, em função do alto coeficiente de variação apresentado nos resultados, não se pode afirmar que os ciclos de saturação e secagem tenham sido positivos para a capacidade do papel se estender até a ruptura.

\section{CONSIDERAÇÕES FINAIS}

As sacarias de papel kraft de materiais da construção apresentam grande potencial para serem reaproveitadas sendo aplicadas em compostos cimentícios. Os resultados de absorção de água apresentam-se mais baixos em relação a fibras vegetais já estudadas e sua relação de aspecto 62,5 apresenta-se ideal para permitir uma boa ancoragem e suportar tensões sem ruptura.

As variações encontradas dentro da indústria papeleira de sacarias kraft para embalagens de diferentes materiais, não parecem interferir ou limitar o seu uso em compósitos, pois as características das fibras individuais não são alteradas.

Quanto ao aspecto de durabilidade, as fibras não foram afetadas pelas variações bruscas de temperatura e umidade, seu alto valor de grau de polimerização, acima de 850 e o baixo teor de lignina, indicam uma resistência ao meio alcalino.

Sendo assim, as fibras das sacarias de papel kraft são um resíduo potencial para ser reaproveitado na produção de compósitos cimentícios para a construção civil. 


\section{AGRADECIMENTOS}

Aos patrocinadores da pesquisa InterCement, Ical, ANVI, Laboratório Carlos Campos e Pontal Engenharia.

Ao Laboratório Multiusuário de Microscopia de Alta Resolução - LabMic, da UFG, pela realização das imagens de microscopia.

À CELG DISTRIBUIÇÃO S.A. - CELG D, em nome do Sr. Marcos Reginaldo Blanco, pela realização dos ensaios de Grau de Polimerização. 


\section{REFERÊNCIAS}

BALLONI, C. J. V. Caracterização física e química da madeira de pinus elliottii. 2009. 42 f. Monografia (Graduação em Engenharia Industrial Madeireira) - Universidade Estadual Paulista, Itapeva, 2009.

COPUR, Y.; TOZLUOGLU, A. A comparison of kraft, PS, Kraft - AQ and Kraft - $\mathrm{NaBH}_{4}$ pulps of Brutia pine. Bioresource Technology, Science Direct, v. 99, p 909-913, 2007.

FOELKEL,C.E.B. Celulose kraft de pinus spp. O Papel. n.1, p.49-67, São Paulo, 1976.

LAURIANO, L. A. Como anda a gestão da sustentabilidade no setor da construção? 2013. Relatório de Pesquisa, Fundação Dom Cabral, Nova Lima, 2013.

MAGALHÃES, A. C. T. V. Estudo de fibras vegetais, mucilagem de cacto e gesso em componentes construtivos. 2009. 142 f. Dissertação (Mestrado em Arquitetura e Urbanismo) Faculdade de Arquitetura e Urbanismo, Universidade de Brasília, Brasília, 2009.

MATINS, M. A. Furfuraldeído - um indicador prático da degradação térmica do papel kraft de transformadores. Ciência e Tecnologia dos Materiais. v. 19, nº 1/2, 2007.

DOS ANJOS, M. A. S.; GHAVAMI, K,; BARBOSA, N. P. Uso de polpa de bambu como reforço de matrizes cimentícias. Revista Brasileira de Engenharia Agrícola e Ambiental. v. 7, 10 f. ISSN $1807-1929$

MORAES NETO, S. P.; TELES, R. F.; RODRIGUES, T. O. Caracterização da madeira de cinco procedências de Pinus tecunumanii implantadas no cerrado do DF. Boletim de Pesquisa e Desenvolvimento - Embrapa, v. 233, 23 p., 2009. ISSN 1676 - 918X.

SAVASTANO, H. J. Materiais à base de cimento reforçados com fibra vegetal: reciclagem de resíduos para a construção de baixo custo. 200. 152f. Tese (Doutorado em Engenharia) Departamento de Engenharia de Construção Civil, São Paulo, 2000.

ZIRBES, R.; ROLIM, J. G.; ZÜRN, H. H. Metodologias para avaliação e diagnóstico do estado de isolamento de papel impregnado com óleo mineral. Revista Controle \& Automação. v. 16, $\mathrm{n}^{\mathrm{o}} 3,2005$. 